\title{
Use of fluorescent probes to monitor the efflux transporters P. Glycoprotein and MRP1 in BeWo cells.*
}

\author{
D.Nedra Karunaratne ${ }^{\mathbf{k}^{*}}$ and Kenneth L. Audus ${ }^{2}$ \\ 1 Department of Chemistry, University of Peradeniya, Peradeniya. \\ 2 Department of Pharmaceutical Chemistry, University of Kansas, Lawrence, KS, U.S.A.
}

Revised: 09 January 2007 ; Accepted: 19 January 2007

\begin{abstract}
Rhodamine, Fluorescein and the Acetoxy Methyl (AM) derivative (calcein AM) of the fluorescent indicator calcein were used to evaluate the functional role of the efflux transport system in BeWo cells. Uptake studies with P-glycoprotein or MRP1 inhibitors show significant enhancement of accumulation of calcein. Since both calcein and calcein AM are extruded by MRP1, whereas only Calcein AM is a substrate of P-glycoprotein, the effect of modulators on the transport of calcein AM is indicative of the functional activity of both P-glycoprotein and MRP1. However, studies with rhodamine (substrate of P-glycoprotein) did not reveal the expected functional activity in the presence of the same modulators. Uptake of Fluorescein (substrate of MRP1) increased in the presence of inhibitors of MRP1, but was unaffected by P-glycoprotein inhibitors.
\end{abstract}

It was found that cyclosporinA, verapamil, indomethacin, probenecid, sodium orthovanadate and vinblastine affected the uptake, efflux and transport of calcein. All of the modulators except sodium orthovanadate and sodium azide increased the uptake of calcein. The transport was polarized with greater permeability from the apical to the basolateral direction. The inhibition of MRP1 and Pgp resulted in a decrease of apical to basolateral transport. However, none were able to decrease transport from basolateral to the apical side significantly. The efflux of calcein was decreased by all the compounds tested, indicating an inhibition of MRP1. Sodium orthovanadate also decreased the efflux but did not affect transport. Therefore, we believe that calcein AM can be used as an indicator of Pgp and MRP1 functional activity in BeWo cells. Fluorescein uptake was only affected by MRP1 inhibitors. P-glycoprotein inhibitors Verapamil and C219 had no effect on the uptake of fluorescein, suggesting that it is an effective indicator of MRP1 functionality. However the transport of fluorescein did not show polarization. This may be due to fluorescein showing a permeability $\left(\sim 1 \times 10^{-5} \mathrm{cms}^{-1}\right)$ ten times greater than that of calcein. Finally, rhodamine cannot be used as a functional indicatior of P-glycoprotein activity in BeWo cells due to the presence of other transporters which interfere with rhodamine uptake and transport.

Keywords: BeWo cells, calceinAM, fluorescein, MRP1, Pglycoprotein, rhodamine

\section{INTRODUCTION}

The BeWo cell line derived from a human choriocarcinoma ${ }^{1}$ produces confluent monolayers displaying properties of normal trophoblasts. However, primary cultures of human trophoblasts do not form monolayers ${ }^{2}$. Therefore, the use of the BeWo cell line serves as a model for the study of transport of compounds across the maternal-fetal barrier. Although tKe placenta transports many substances by passive diffusion, the active efflux transporters $\mathrm{P}$-glycoprotein $(\mathrm{Pgp})^{3}$, Multidrug Resistance Associated Protein (MRP1) ${ }^{4,5}$ and Breast Cancer Resistance Protein (BCRP) ${ }^{6}$ have now been found to be present in Bewo cells and the placenta. Efflux pump activity affects efficient drug delivery and acts as a mechanism of drug resistance ${ }^{7}$.

The placental transporters are of vital importance during pregnancy. These transporters ensure that the nutrients are provided to the fetus, and metabolites are efficiently effluxed from the uterus. Drug transporters similarly protect the fetus from adverse effects by effluxing drugs present in the maternal circulation. Thus, the function of drug transporters and substances capable of modulating these transporters need to be carefully studied.

Although the existence of Pgp in the placenta is well known, an understanding of the functional activity at the

\footnotetext{
* Corresponding author

${ }^{* *}$ Part of this work was presented at the Peradeniya University Research Sessions 2005, Peradeniya.
} 
cellular level is very limited. The current study examines the functional activity of both Pgp and MRP1 by comparing the effect of Pgp and MRP1 inhibitors on the uptake, efflux and transport of acetoxy methyl derivative of calcein (calcein AM) (chemical structures in page 336) in BeWo cells. We have used calcein AM, a non fluorescent hydrophobic compound which is hydrolyzed to the fluorescent anion calcein by cytoplasmic esterases. Calcein AM is the nonfluorescent acetoxy methyl ester (AM) of the fluorescent compound, calcein. Calcein is a substrate of MRP1, but not of Pgp. However, the ester calcein AM is a substrate of both Pgp and MRP1 ${ }^{8}$. Pgp extrudes calcein AM from the plasma membrane, reducing accumulation of calcein in the cytosol. The amount of Pgp activity is inversely proportional to the accumulation of intracellular calcein fluorescence. Rhodamine is generally a good marker for functional Pgp activity ${ }^{9}$. However, we were unable to obtain significant increases in uptake or see a polarization in transport of rhodamine. Rhodamine is a cationic dye, unlike the anionic compounds, fluorescein and calcein (chemical structures in page 336). On the other hand, uptake of fluorescein yielded the expected results with MRP1 inhibitors and is an effective tool for assessment of MRP1 functionality.

\section{METHODS AND MATERIALS}

Materials: Calcein AM and MK571 were obtained from Molecular Probes. 1-Methyl-4-phenyl-pyridinium Iodide (MPP+) was from Research Biochemicals International, MA, USA. Calcein, rhodamine 123 and fluorescein were from Sigma Chemicals (St. Louis, MO, USA). $10 \mathrm{mM}$ non-essential amino acids and $10,000 \mathrm{U} / \mathrm{mL}$ penicillin $/ 10 \mathrm{mg} / \mathrm{mL}$ streptomycin were purchased from Gibco BRL, and Foetal Bovine Serum (FBS) from Atlanta Biologicals, GA. Bicinchoninic acid (BCA) protein assay reagent was purchased from Pierce. ${ }^{14} \mathrm{C}$ sucrose was from Perkin Elmer, Boston, MA,USA.

Cell culture: The BeWo cell line was originally derived from a human choriocarcinoma ${ }^{1}$. The BeWo clone (b30) was obtained from Dr. Alan Schwartz (Washington University, St. Louis, MO, USA). The cells were continuously cultured in Dulbecco's Modified Eagle's Medium (DMEM) with $10 \%$ heat inactivated FBS containing $0.37 \%$ sodium bicarbonate, $2 \mathrm{mM} \mathrm{L}$-glutamine, $0.1 \mathrm{mM}$ non-essential amino acids and $1 \%$ antibiotics $(10,000 \mathrm{U} / \mathrm{mL}$ penicillin and $10 \mathrm{mg} / \mathrm{mL}$ streptomycin $)$. The cells were maintained in $175-\mathrm{cm}^{2}$ Falcon flasks at $\mathrm{pH} 7.4$ under $5 \% \mathrm{CO}_{2}$ and $95 \%$ humidity at $37{ }^{\circ} \mathrm{C}$. After $4-5$ of culture, the cells were ready for passage. The cells were harvested by exposure ( $5 \mathrm{~min}$ ) to a trypsin-EDTA solution $(0.25 \%$ trypsin and $0.2 \%$ Ethylene diamine tetra-acefic acid (EDTA) in Hank's Balance Salt solution or HBSS). Cells were passed onto $12 \mathrm{~mm}$ Transwell polyester membranes previously coated with type IV human placental collagen $(0.75 \mu \mathrm{g} / \mathrm{mL}, 70 \mu \mathrm{L} / \mathrm{insert}:$ Sigma) for monolayer cultures. The seeding density was 50,000 cells per well. Uptake and efflux experiments were performed in 12 well culture plates precoated with Poly-D-Lysine $(5 \mu \mathrm{g} / \mathrm{mL}$ solution, $100 \mu \mathrm{L}$ per well), sterilized, and coated with fibronectin $(50 \mu \mathrm{g} / \mathrm{mL}, 4$ drops per well) Cells were seeded at a density of 50,000 cells per well. The culture medium was changed every other day. Cells formed monolayers or were confluent in 4-5. For consistency, experiments were performed on the $5^{\text {th }}$ day post seeding.

Uptake studies: Accumulation of rhodamine $123(0.5,1$ and $5 \mu \mathrm{M})$, Calcein ( $1 \mu \mathrm{M}$ CAM) and fluorescein (1 and $100 \mathrm{mM}$ ) was investigated in BeWo cells. On the $5^{\text {th }}$ day post seeding of culture plates, the growth medium was aspirated off and the cells were rinsed three times with pre-warmed $\left(37^{\circ} \mathrm{C}\right) \mathrm{HBSS}$. The monolayers were then equilibrated for $30 \mathrm{~min}$ in $1 \mathrm{~mL} \mathrm{HBSS}$ at $37^{\circ} \mathrm{C}$. HBSS was aspirated and the fluorescent indicator was added without inhibitor (for control), while appropriate inhibitor was added to the indicator solution for the experimental wells $(1 \mathrm{~mL} / \mathrm{well})$. The wells were incubated for $1 \mathrm{~h}$ with gentle shaking. Thereafter, the wells were aspirated and washed 3 times with ice cold HBSS. The cells were lysed with lysing solution $(2 \% \mathrm{v} / \mathrm{v}$ Triton $\mathrm{X}-100$ for calcein accumulation, and $0.5 \% \mathrm{v} / \mathrm{v}$ Triton $\mathrm{X}-100$ in $0.2 \mathrm{~N} \mathrm{NaOH}$ for rhodamine and fluorescein accumulation). The lysates were then assayed using a fluorescent spectrophotometer (SLM instruments, Inc.). Fluorescence was measured at excitation $485 \mathrm{~nm}$ and emission $530 \mathrm{~nm}$ and quantified against a standard curve of Rh123, calcein or sodium fluorescein. The protein content of each monolayer was determined using the BCA protein assay reagent kit. The results are expressed as total fluorescent probe accumulation ( $\mathrm{nmol}$ or $\mathrm{pmol}$ ) per $\mathrm{mg}$ of protein.

Efflux experiments: Cell seeding and growth conditions were identical to those utilized in accumulation experiments. Three methods were utilized for efflux assay. The first involved accumulation of fluorescent probe in the presence of the inhibitor used for efflux. Accumulation of probe for the other two methods was in the absence of the modulator. Accumulation was performed as mentioned in uptake studies. After one hour of uptake of probe, the monolayers were washed with ice cold HBSS as before, and then pre-warmed $\left(37^{\circ} \mathrm{C}\right)$ efflux solutions $(1 \mathrm{~mL}$ per well) were added. In the first two methods, the efflux solutions were HBSS with or without (control) the appropriate modulator. Efflux was monitored for a time of $2 \mathrm{~h}$. In the third method, efflux for the first hour was in the absence of any modulator. Modulator was added at the $59^{\text {th }}$ minute and then efflux monitored for a further two hours. At suitable time intervals, $100 \mu \mathrm{L}$ aliquots were 
removed for fluorescent assay and replenished with $100 \mu \mathrm{L}$ of the respective efflux solution. The fluorescent probe effluxed was quantitated against a standard curve. At the end of the two hour efflux period, the monolayers were washed with ice cold HBSS and lysed in lysing solution, and the cell associated fluorescence and protein content were measured. Results are expressed as pmol fluorescent probe effluxed per mg protein, and pmol cell associated fluorescent probe per $\mathrm{mg}$ protein.

Transport studies: BeWo cells were seeded onto human placental collagen pre-coated polyester transwells. The cells were allowed to attach for $24 \mathrm{~h}$, then the medium in the apical and basolateral compartments were removed and new media added every two days. Transport was performed on the $5^{\text {th }}$ or $6^{\text {th }}$ day post seeding. The Trans Epithelial Electrical Resistance (TEER) for BeWo monolayers were measured and found to be very low (90 $\left.-150 \Omega \mathrm{cm}^{2}\right)^{10}$. Therefore, the integrity of the membranes were assessed by performing a ${ }^{14} \mathrm{C}$-sucrose flux for $1 \mathrm{~h}$ after the fluorescent probe transport assay. Vectorial transport of calcein AM, fluorescein or rhodamine was investigated in the presence or absence of the inhibitor. The receiver compartment contained HBSS and the inhibitor, while the donor contained the fluorescent probe and the inhibitor (the control did not have the inhibitor in both compartments). The volume on the apical side was $1.0 \mu \mathrm{L}$ and the basolateral compartment had $2.0 \mu \mathrm{L}$. At various time intervals, a $100 \mu \mathrm{L}$ sample was removed from the receiver compartment and replaced immediately with an equal volume of the receiver solution. Transport was performed for $2 \mathrm{~h}$. The monolayers were then rinsed in ice-cold HBSS and sucrose flux assay performed.

Data Analysis: Apparent permeability coefficients $\left(\mathrm{P}_{\text {app }}\right)$ were calculated according to the following equation:

$$
\left(\mathrm{P}_{\text {app }}\right)=\{(\mathrm{dQ} / \mathrm{dt}) \cdot \mathrm{V}\} / \mathrm{A} \cdot \mathrm{C}_{\mathrm{o}}
$$

Where $\mathrm{V}$ is the volume of the receiver chamber, $\mathrm{A}$ is the area of the monolayer, $\mathrm{C}_{\mathrm{o}}$ is the initial donor concentration, and $\mathrm{dQ} / \mathrm{dt}$ is the flux of the probe.

Kinetic studies analysis: The rate of uptake was measured in uptake studies performed with rhodamine, fluorescein or with fluorescein in the presence of $10 \mu \mathrm{M} \mathrm{MK} 571$ at concentrations ranging from $1-150 \mu \mathrm{M}$. The fluorescent probes were allowed to be accumulated by the cells for 5 , 10,15 and $30 \mathrm{~min}$ and quenched at the designated times with ice cold HBSS. The cells were lysed and assayed as described above in uptake studies.

The results were analyzed by Michaelis -Menten kinetics using the equation:

$$
\mathrm{V}=\frac{\mathrm{Vmax}[\mathrm{S}]}{\mathrm{Km}+[\mathrm{S}]}
$$

in the Sigma plot programme.

\section{RESULTS}

\section{Calcein accumulation and efflux}

The accumulation of calcein in BeWo cells after uptake of $1 \mu \mathrm{M}$ Calcein AM for $1 \mathrm{~h}$ our was carried out in the presence and absence of selected agents (Figure 1). The Pgp inhibitors cyclosporinA and verapamil, and the Pgp/ MRP 1 inhibitor, vinblastine and the MRP 1 inhibitors indomethacin and probenecid (at $500 \mu \mathrm{M}$ only) all significantly increased calcein/ calcein AM uptake. However, sodium orthovanadate and sodium azide which inhibit ATPase activity, decreased the accumulation of calcein in the cells. C219, a mouse monoclonal antibody to MDR1 (Pgp) also increased the uptake in a manner similar to cyclosporinA. Hence, inhibitors of Pgp and MRP1 increase the cellular uptake of calcein AM.

\section{Uptake of Calcien Al}

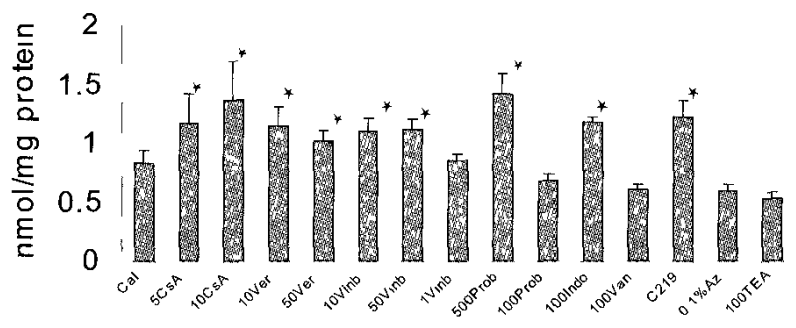

Figure 1: Uptake of $1 \mu \mathrm{M}$ Calcen $\mathrm{AM}$ in the presence of various inhibitors over a period of 1 hour All data points were performed in quadruplicate. The concentrations of inhibitors are in $\mu \mathrm{M}$ Az1de used was $0.1 \%$ Antibody C219 was diluted 140 Stars indicate significant increase in uptake by students $T$ test. ( $p<005$ compared with control).

Monitoring the efflux of calcein from loaded cells revealed the function of the efflux protein MRP1 in releasing calcein into the external medium. In two different experiments, calcein AM was loaded into the cells in the presence (Figure 2a) or in the absence (Figure 2b) of the inhibitors. The efflux was then monitored for two hours in the presence of the respective inhibitor. When the cells were loaded in the presence of the respective Pgp inhibitors, cyclosporin A showed a small increase, but verapamil (at 5 and $50 \mu \mathrm{M}$ ) did not greatly affect the amount of calcein effluxed from the cells. However, MRP1 inhibitors vinblastine and indomethacin decreased efflux 
during the two hour efflux period (Figure 2a). The intracellular calcein retention post efflux showed the same trend of increased calcein concentrations as seen for uptake in the presence of all the inhibitors except vanadate which had a very low intracellular calcein concentration. The high intracellular calcein concentration observed with loading cells in the presence of cyclosporin A may account for the increased "efflux" if passive diffusion comes into play. This is a likely explanation as evidenced in Figure $2 b$ where cyclosporin A did not greatly affect the efflux when cells were loaded without the inhibitor to ensure equal intracellular calcein concentrations. The efflux of calcein when cells were allowed to take up calcein AM in the absence of inhibitors, but effluxed in the presence of

Effect of inhibitors on uptake and efflux of Calcein

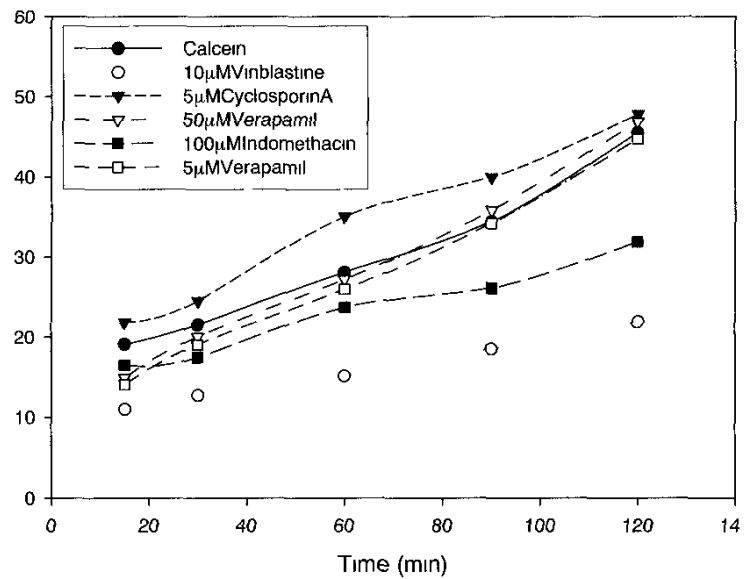

(a) Cells loaded in the presence of inhibitor and effluxed in the presence of inhibitor. inhibitors, is shown in Figure $2 b$. Orthovanadate and the MRP inhibitor indomethacin decreased the efflux of calcein as expected. To further clarify the effect on efflux, a third experiment was performed wherein the cells were loaded in the absence of inhibitors, then allowed to efflux in the absence of inhibitors, until inhibitors were added at the $59^{\text {th }}$ minute. Thereafter efflux was monitored in the presence of inhibitor for two hours (Figure 2c). This strategy resulted in a distinct decrease in efflux after addition of inhibitors for all compounds tested (except $1 \mu \mathrm{M}$ vinblastine). Thus, the effect of these inhibitors on the efflux protein MRPl can be observed in this experiment.

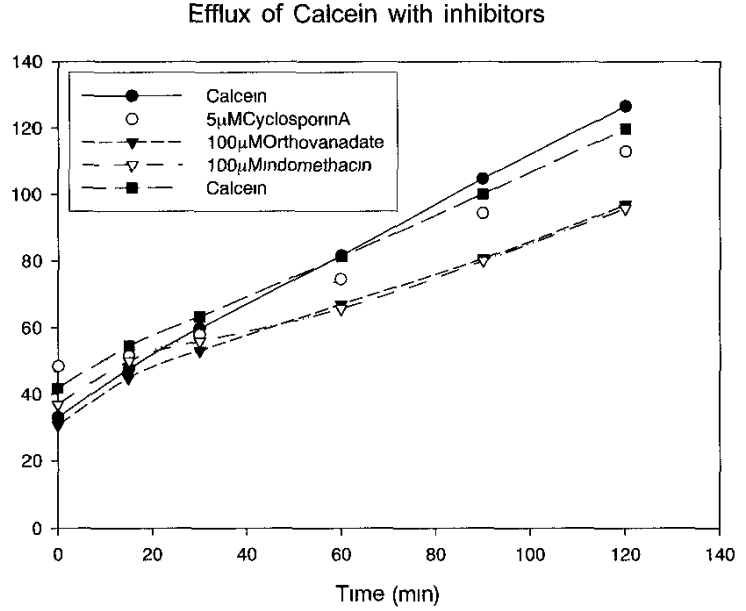

(b) Cells loaded in the absence of inhibitor and effluxed in the presence of inhibitor.

Effect of inhibitors on efflux of calcein

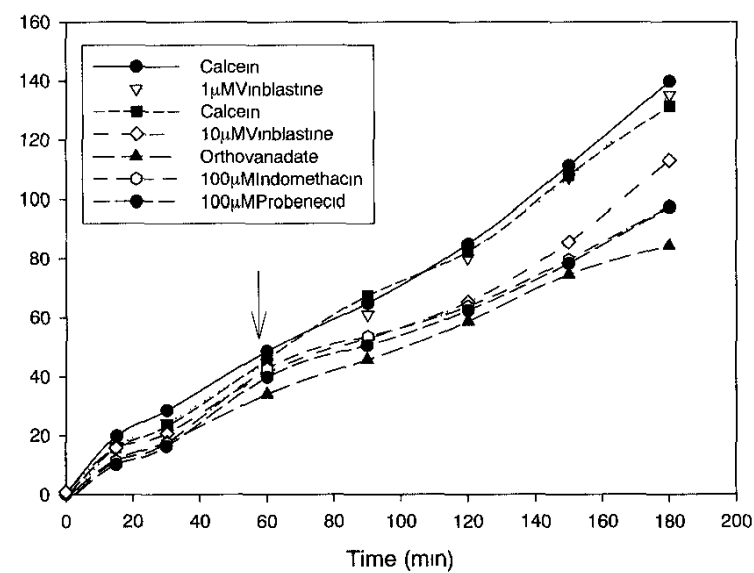

(c) Cells loaded in the absence of inhibitor, effluxed for 1 hour without inhibitor and then added inhibitor and effluxed a further two hours. Arrow indicates point of addition of inhibitors.

Figures 2: Efflux of Calcein decreased on addition of Pgp and MRP1 inhibitors. The average of 4 experimental wells were taken for each data point 


\section{Effect of modulators on uptake of rhodamine.}

Rhodamine accumulation by $\mathrm{BeW}$ o cells was measured at $0.5 \mu \mathrm{M}, 1 \mu \mathrm{M}$ and $5 \mu \mathrm{M}$ rhodamine concentrations in the presence of several modulators of both Pgp and MRP1. The inhibitors used were cyclosporin $\mathrm{A}(5$ and $10 \mu \mathrm{M}), 50 \mu \mathrm{M}$ verapamil, $100 \mu \mathrm{M}$ indomethacin, $100 \mu \mathrm{M}$ probenecid, $100 \mu \mathrm{M}$ sodium orthovanadate, $10 \mu \mathrm{M}$ vinblastine, $500 \mu \mathrm{M}$ triethylamine hydrochloride, $100 \mu \mathrm{M}$ dipyradamole, $100 \mu \mathrm{M}$ Quinidine, $100 \mu \mathrm{M} \mathrm{MPP}^{t}, 0.1 \%$ sodium azide and $\mathrm{C} 219$. Pre incubation with azide and consequent treatment with cyclosporin A and triethylamine was also performed. None of the modulators tested above were able to significantly increase the uptake of rhodamine into BeWo cells. The same was observed when a combination of two inhibitors from $\mathrm{MPP}^{+} / \mathrm{TEA} /$ cyclosporin A were used. (All results not shown).

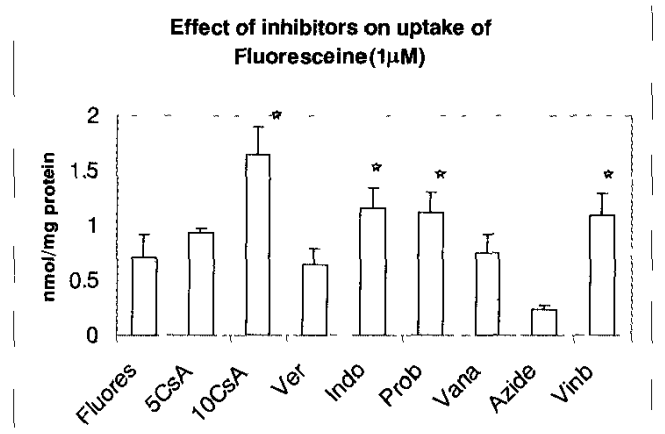

a) Uptake of $1 \mu \mathrm{M}$ fluorescein. The inhibitors tested were 5 and $10 \mu \mathrm{M}$ cyclosporin A, $50 \mu \mathrm{M}$ verapamil, $100 \mu \mathrm{M}$ indomethacin, probenecid and orthovanadate, and $0.1 \%$ azide respectively

\section{Effect of modulators on uptake of fluorescein.}

Accumulation of fluorescein was measured at two concentrations. At a fluorescein concentration of $100 \mu \mathrm{M}$, modulators had no effect on uptake (results not shown). This could be due to saturation of the efflux pump at high concentration. When uptake was performed using $1 \mu \mathrm{M}$ fluorescein, MRP1 inhibitors were able to increase the uptake of fluorescein, but Pgp in inhibitors had no effect (Figure 3). Again, the ATPase inhibitors, azide and orthovanadate did not increase uptake.

\section{Kinetics of rhodamine and fluorescein uptake.}

Effect of rhodamine concentration on uptake was measured and $\mathrm{Km}$ was obtained as $229.7 \mu \mathrm{M}$ (Figure 4a). Vmax was found to be $0.49 \mathrm{nmol} / \mathrm{mg}$ protein $/ \mathrm{min}$. Kinetics of fluorescein uptake indicated a $\mathrm{Km}$ of $247.9 \mu \mathrm{M}$ and a

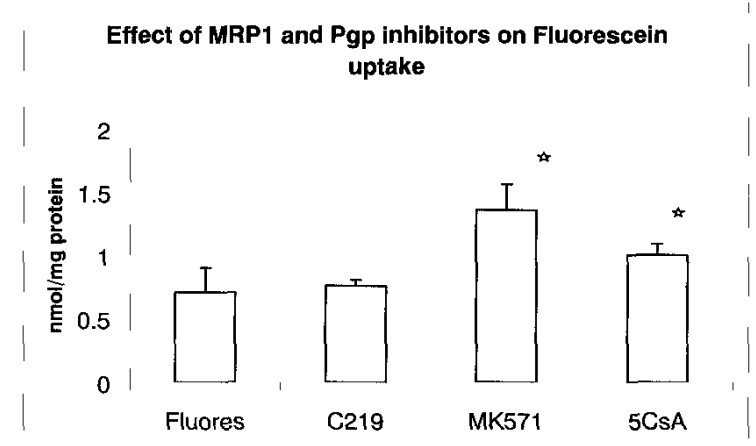

b) The effect of the P-glycoprotein inhibitor C219 diluted 1:50, and MRP1 inhibitor MK571 (10 $\mu \mathrm{M})$ and $5 \mu \mathrm{M}$ cyclosporin A on uptake of $1 \mu \mathrm{M}$ fluorescein.

Figures 3: Effect of inhibitors on fluorescein uptake. Each data point is an average of four wells. Stars indicate significant increase in uptake by students $T$ test. ( $p<0.05$ compared with control).

Plot of $V$ vs [S] for rhodamine uptake

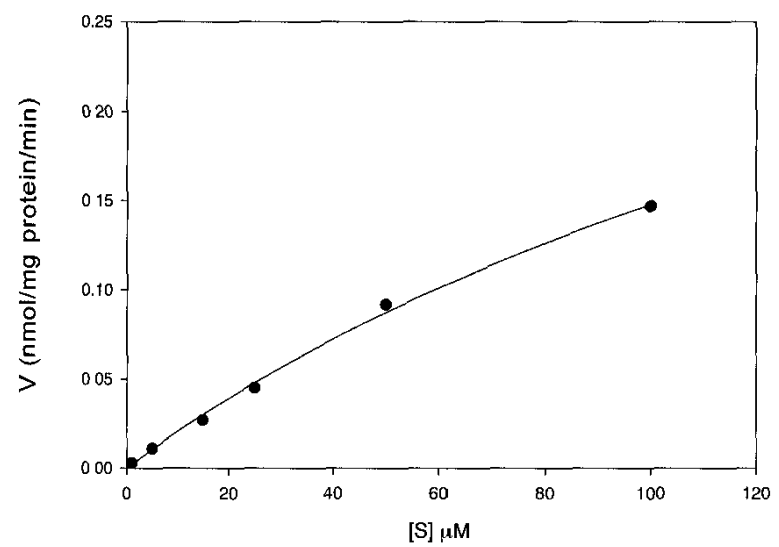

Figures 4a: Kinetics of rhodamine uptake. Each data point was performed in quadruplicate
Plot of $V$ vs [S] for fluorescein uptake

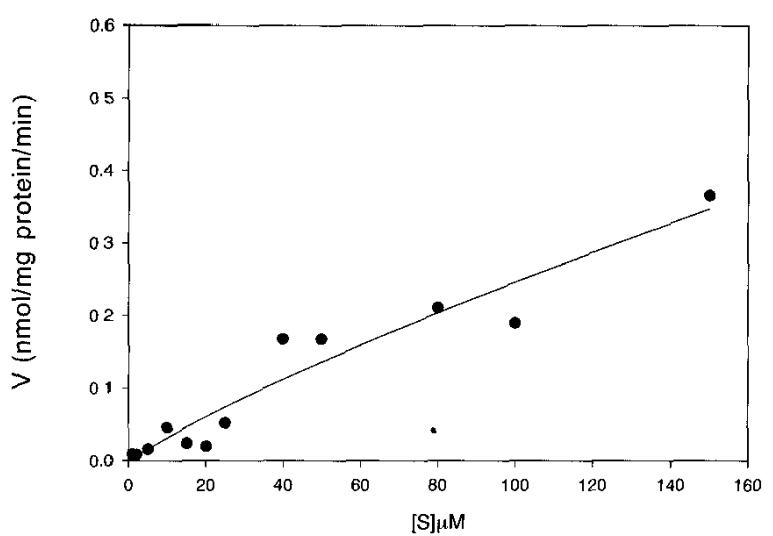

Figures 4b: Kinetics of fluorescein uptake. Each data point was performed in quadruplicate 


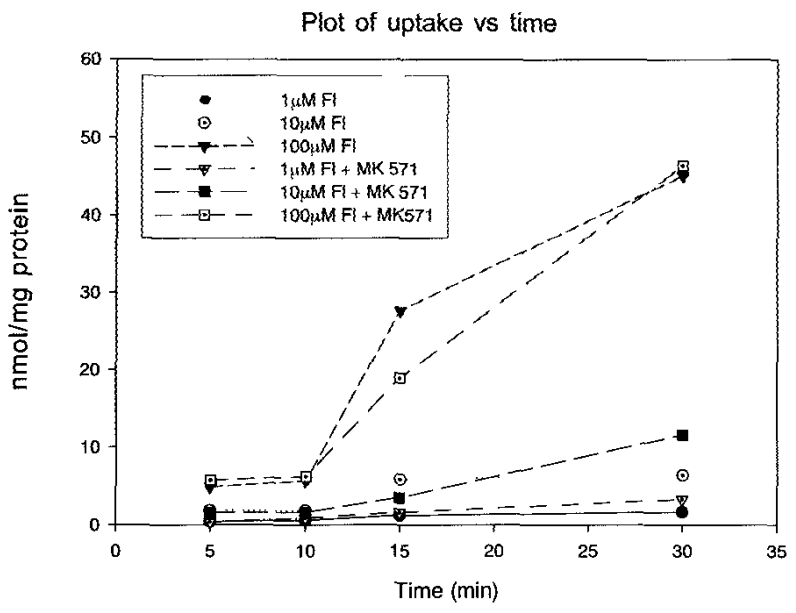

Figures 5: The effect of MK 571 on the uptake of fluorescein with time. Each data point is an average of four wells. $\mathrm{Fl}=$ fluorescein. The MK 571 concentration was $10 \mu \mathrm{M}$.

Rhodamine 123<smiles>COC(=O)c1ccccc1-c1c2ccc(=[NH2+])cc-2oc2cc(N)ccc12</smiles><smiles>CC(=O)COC(C)=O</smiles>

Calcein AM

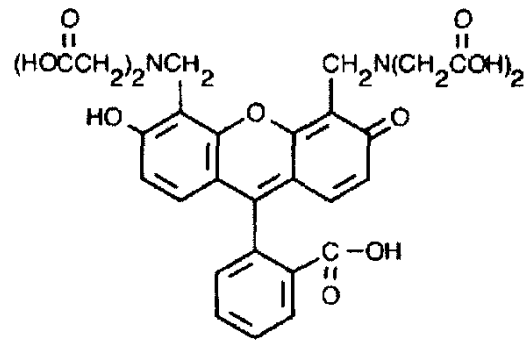

Fluorescein<smiles>O=C(O)c1ccccc1-c1c2ccc(=O)cc-2oc2cc(O)ccc12</smiles>

Structures of rhodamine, fluorescien, calcein and calceinAM.
Vmax of $1.58 \mathrm{nmol} / \mathrm{mg}$ protein/min (Figure $4 \mathrm{~b}$ ). An uptake study of fluorescein at varying concentrations with and without the presence of the inhibitor MK571 indicated that uptake in the first 10 minutes was not affected by the inhibitor. However low fluorescein concentrations ( 1 and $10 \mu \mathrm{M}) \mathrm{MK} 571$ increased the overall uptake in 30 minutes (Figure 5). At $100 \mu \mathrm{M}$ concentration, the inhibitor did not increase uptake as was seen here as well as in previous studies 3 . From this data, the rate of passive influx was calculated to be 0.05 and efflux to be $0.07 \mathrm{nmol} / \mathrm{mg}$ protein/ $\min$ at $1 \mu \mathrm{M}$, and 0.18 and $0.33 \mathrm{nmol} / \mathrm{mg}$ protein $/ \mathrm{min}$ respectively at $10 \mu \mathrm{M}$ fluorescein concentration. At these concentrations the rate of influx is less than the rate of efflux which accounts for the MDR effect. The rate of influx at $100 \mu \mathrm{M}$ concentration, was $1.71 \mathrm{nmol} / \mathrm{mg}$ protein/ min, which is much greater than the rate of efflux which was $0.18 \mathrm{nmol} / \mathrm{mg}$ protein $/ \mathrm{min}$. A notable observation is the low uptake concentration of $\sim 0.2 \mathrm{nmol} / \mathrm{mg}$ protein for uptake at $1 \mu \mathrm{M}$ rhodamine (Figure not shown) in comparison to $\sim 1.0 \mathrm{nmol} / \mathrm{mg}$ protein for uptake at $1 \mu \mathrm{M}$ calceinAM (Figure 1) and fluorescein (Figure 3) in agreement with the 3 fold difference in their Vmax values.

\section{Transport of rhodamine and fluorescein.}

Transport of $5 \mu \mathrm{M}$ rhodamine was performed and values of $1.1-1.8 \times 10^{-5} \mathrm{cms}^{-1}$ were obtained for apical to basolateral direction. The values for the basolateral to apical direction ranged from $1.0-1.8 \times 10^{-5} \mathrm{cms}^{-1}$. Thus there was no polarized transport. These values did not change significantly when transport was performed in the presence of the inhibitors cyclosporin $A$ or verapamil and remained in the range $1.4-$ $1.6 \times 10^{-5} \mathrm{cms}^{-1}$ for transport in both directions.

Fluorescein transport for the apical to basolateral direction was almost similar to that of the basolateral to apical direction. The inhibitors cyclosporin $\mathrm{A}$, indomethacin and MK 571 resulted in a small decrease in the permeability ratio, which was not significant (Table 1). The intracellular fluorescein accumulation was found to be two fold greater for apical loading than for basolateral loading as observed in the case of calcein accumulation during transport (Table 2). These transport values are comparable to transport values of 1.0-1.5 x $10^{5} \mathrm{cms}^{-1}$ obtained for rhodamine and sucrose. The transport of fluorescein across membranes coated with collagen only and devoid of BeWo cells was $2.8 \times 10^{-5} \mathrm{cms}^{-1}$ in both directions.

\section{Transport of calcein across monolayers.}

Calcein showed polarized transport in the apical (AP) to basolateral (BL) direction. Measurement is made of the calcein that is transported across the monolayer. In all cases, the intracellular calcein accumulated for the AP to 
Table 1: Effect of inhibitors on the transport of fluorescein.

\begin{tabular}{lccc} 
Inhibitor & $\begin{array}{c}\text { Permeability AP-BL } \\
\times 10^{-5} \mathrm{cms}^{-1}\end{array}$ & $\begin{array}{c}\text { Permeabihty BL-AP } \\
\times 10^{-5} \mathrm{cms}^{-1}\end{array}$ & Ratio BL/AP \\
none & 0.93 & 0.93 & 1.0 \\
Cyclosporm A & 0.93 & 0.75 & 0.9 \\
Indomethacin & 1.04 & 0.89 & 0.9 \\
MK 571 & 1.13 & 0.96 & 0.9 \\
\hline
\end{tabular}

Table 2: Effect of inhibitors on the permeability of calcein, and the residual intracellular concentration.

\begin{tabular}{|c|c|c|c|c|c|}
\hline \multirow[t]{2}{*}{ Inhibitor } & \multicolumn{2}{|c|}{$\begin{array}{c}\text { Cellular Calcein conc } \\
\text { pmol calcein }\end{array}$} & \multicolumn{2}{|c|}{$\begin{array}{l}\text { Permeability } \\
\text { x } 10^{-6} \mathrm{cms}^{-1}\end{array}$} & \multirow[t]{2}{*}{$\begin{array}{l}\text { Ratio } \\
\text { BL/AP }\end{array}$} \\
\hline & AP-BL & BL-AP & AP-BL & BL-AP & \\
\hline None & 152.8 & 24.4 & 1.7 & 1.2 & 0.7 \\
\hline Cyclosporin A & 213.8 & 53.0 & 1.0 & 1.2 & 1.2 \\
\hline Verapamil & 180.6 & 42.2 & 1.5 & 1.2 & 0.8 \\
\hline Indomethacin & 192.6 & 61.3 & 0.9 & 1.2 & 1.3 \\
\hline Orthovanadate & 75.3 & 7.8 & 1.5 & 0.7 & 0.5 \\
\hline
\end{tabular}

BL direction was 3-6 times higher than the intracellular calcein retained for the BL to AP direction (Table 2). This was much greater than the difference observed with fluorescein.

In the case of orthovanadate, the BL loading intracellular concentration was 10 times less than the $\mathrm{AP}$ loading intracellular concentration. The permeability values obtained indicate that BL-AP permeability is not affected in all cases except with orthovanadate (Table 2). The AP-BL permeability is decreased in all cases. However the ratio of basolateral to apical transport did not reach unity in any of these cases. Thus, transport is complicated due to the fact that both MRP1 and Pgp act on the transport of calcein and efflux of calcein AM. The result observed with sodium orthovanadate was a decrease in the Basolateral to Apical transport ratio, which was not seen with any of the other inhibitors. ${ }^{14} \mathrm{C}$ Sucrose transport was measured for membrane integrity. The permeability value for paracellular transport of sucrose was $1.5 \times 10^{-5} \mathrm{cms}^{-1}$. The permeability values obtained for calcein transport was approximately 10 fold lower than those of fluorescein and rhodamine transport.

\section{DISCUSSION}

Fluorescent probes are useful indicators for assessing whether compounds are inhibitors or modulators of Pgp. This study was performed as a comparison of the transport properties of three fluorescent indicators in BeWo cells. Rhodamine contains a positive charge whereas calcein and fluorescein are negatively charged. Calcein AM is a neutral molecule. Several workers have reported the use of rhodamine as a marker for the study of uptake and transport in many cell systems ${ }^{9,11}$. Since we were unable to observe the expected results with rhodamine, calcein AM and fluorescein were selected as the probes. We found that the predicted results were obtainable with both these probes in uptake studies: MRP1 and Pgp inhibitors affected the uptake of calcein AM (Figure 1) and only MRP1 inhibitors had an effect on the uptake of fluorescein (Figure $3 \mathrm{a}, \mathrm{b}$ ). When $100 \mu \mathrm{M}$ fluorescein was used, there was no effect on the uptake by any of the modulators. An earlier study 3 using $100 \mu \mathrm{M}$ fluorescein was interpreted as a sign of absence of MRP1 expression in BeWo cells. However, the presence of MRP1 mRNA in BeWo cells has been confirmed ${ }^{5,12}$. This lack of effect by modulators observed earlier was likely due to a saturation of the efflux protein (MRP1) at high fluorescein substrate concentration. It has been shown that the rate of Pgp mediated efflux must be greater than the rate of transmembrane passive influx to observe the effect of modulators ${ }^{13}$. The efficiency of substrate extrusion depends on slow passive transmembrane movement. At low concentration ( $1 \mu \mathrm{M}$ fluorescein), the passive permeability effect is minimal, and therefore the modulators influence the uptake of the fluorescent substrate $^{14}$. We have shown that at 1 and $10 \mu \mathrm{M}$ 
fluorescein concentrations, the rate of efflux is greater than the passive influx (Figure 5), and that at $100 \mu \mathrm{M}$ the rate of efflux was negligible compared to influx which explains the observation of the MDR effect at $1 \mu \mathrm{M}$ and not at $100 \mu \mathrm{M}$. Fluorescein uptake was increased by the MRP1 inhibitors probenecid, indomethacin, MK571 and vinblastine. Pgp in inhibitors monoclonal antibody $\mathrm{C} 219$ and verapamil did not affect uptake of fluorescein. However, the ability of cyclosporin A to inhibit MRP1 is demonstrated by the increased uptake of fluorescein (Figure 3). We found that fluorescein had a $\mathrm{Km}$ of $247.9 \mu \mathrm{M}$ comparable to that of $229.7 \mu \mathrm{M}$ found for rhodamine and $268 \mu \mathrm{M}$ for calcein ${ }^{15}$.

The efflux of calcein was inhibited by several MRP1 inhibitors. When the cells were loaded with calcein AM in the presence of inhibitors of Pgp or MRP1, the intracellular concentration of accumulated calcein was increased and the efflux was affected by the MRP1 inhibitors only. The $\mathrm{Km}$ for calcein AM is .05 $\mu \mathrm{M}$ for MRP1 and $0.12 \mu \mathrm{M}$ for $\mathrm{Pgp}^{15}$. However, the Km of MRP1 for calcein is $268 \mu \mathrm{M}$. This means that calcein is less efficiently transported than calcein AM. The absence of any effect on the permeability of calcien in the BL to AP direction may be due to the very low intracellular calcein concentration and the high $\mathrm{Km}$ of calcein. Sodium orthovandate is a Pgp inhibitor. It was also shown to bind and inhibit MRP1, but is not transported by MRP ${ }^{16}$. The low uptake of calcein, fluorescein and rhodamine in the presence of sodium orthovandate and sodium azide may be related to the fact that sodium orthovanadate suppresses rhodamine 123 accumulation in primary rat hepatocyte cultures expressing low levels of pgp ${ }^{17}$. However when the cells were pretreated with sodium azide prior to uptake, and uptake performed in the absence of azide, there was no observed suppression of uptake of rhodamine (results not shown). This leads us to assume that the presence of azide (or vanadate) during the entire duration of uptake or transport may lead to toxicity of cells causing a leakiness in the cells. This also explains the decreased uptake of calcein, and the 10 fold decrease in residual calcein retained in cells during transport (Table 2).

Transport of calcein was monitored by addition of calcein AM to the donor compartment and assaying the receiver for appearance of calcein. From the data presented in table 2, it appears that the transport from the basolateral to apical compartment is unaffected by modulators. The greater permeability from apical to basolateral direction may be due to the increased intracellular calcein concentration compared to the low intracellular concentration observed with basolateral to apical transport. It is known that MRP1 is located on the basolateral membranes of hepatocytes ${ }^{18}$, choroid plexis $^{19}$ and kidney cells ${ }^{20}$. The ability of MRPI inhibitors to decrease the AP to $\mathrm{BL}$ permeability supports the basolateral location of MRP1.

Since uptake and transport of rhodamine was not affected by any of the inhibitors used, several different concentrations of rhodamine were tried. However, even at $1 \mu \mathrm{M}$ concentration, there was no increased uptake in the presence of the modulators tested (results not shown). It was not possible to measure fluorescence at concentrations below $1 \mu \mathrm{M}$ and a kinetic study of uptake was attempted to determine the $\mathrm{Km}$ value. $\mathrm{A} \mathrm{Km}$ value of $229.7 \mu \mathrm{M}$ was obtained ${ }^{17}$. have reported that the apparent $\mathrm{Km}$ measured as the dye concentration required for half maximal stimulation of ATPase was found to be $40 \mu \mathrm{M}$. Rhodamine 123 has been shown to have a fast transmembrane movement rate, and lowest dye binding rate when compared to other rhodamine dyes ${ }^{21}$. The lack of the MDR effect with rhodamine may be attributed to a low efflux rate at concentrations below $40 \mu \mathrm{M}$ compared to influx rates at the concentrations tested. Since both fluorescein and calcein are anions, they are substrates of MRP1 which functions as a transporter of amphiphilic anions and natural product anti cancer drugs. Rhodamine is cationic and is not a substrate of the MRP1. In the absence of rhodamine, calcein AM is the only fluorescent probe that can be used to assess the functionality of Pgp. We have successfully used radiolabelled substrates of Pglycoprotein to demonstrate that modulators of Pgp do effect the uptake and transport of the radiolabelled substrate (results not shown). In order to understand the anomaly in the rhodamine uptake, a vinblastine resistant cell line with increased expression of Pgp may be used as a model. The increased expression of Pgp has shown large differences in uptake in vinblastine resistant Caco-2 cells $\mathrm{s}^{22}$.

\section{Acknowledgement}

Funding from NIH grant P01HD39878 is gratefully acknowledged.

\section{References}

1. Patillo R.A. \& Gey G.O. (1968). The establishment of a cell line of human hormone synthesizing trophoblastic cell line in vitro. Cancer Research 28: 1231 - 1236.

2. Liu F. Soares M.J. \& Audus K.L. (1997). Permeability properties of monolayers of the human trophoblast cell line BeWo. American Journal of Physiology 273: C1596C1604.

3. Utoguchi N., Chandorka G.A., Avery M. \& Audus K.L. (2000). Functional expression of P-glycoprotein in primary cultures of human cytotrophoblasts and BeWo cells. Reproductive Toxicology 14: $217-224$. 